\title{
Nuclear Extract
}

National Cancer Institute

\section{Source}

National Cancer Institute. Nuclear Extract. NCI Thesaurus. Code C19832.

Nuclear extracts contain proteins in nuclear compartment of the cell and are used to monitor transcription factor activation in a variety of standard protocols, including electrophoresis mobility shift assay (EMSA), DNA footprinting, Western blotting and preparative purification of nuclear proteins. 